change to build people's capacity and systems to respond effectively to health needs. ${ }^{1}$

\section{Community capacity building}

Capacity building should not be limited to organisations, but should also extend to working with communities to enable them to more actively participate in defining and addressing public health issues. Health organisations often have a central role in building capacity in communities.

\section{Working simultaneously from bottom-up and top-down directions}

The development of high level commitment and action supports the development of local level skills, which in turn builds support within communities and organisations.

\section{CONCLUSION}

The School's work with the Pacific Islands reflects these key principles, which are important to sustain the gains from capacity building. It clearly recognises the need to match the system and the people and to pay attention to the demand side. The development of Guidelines for Healthy Islands, ministerial commitment and national action plans are designed to support the training of key personnel in health promotion to ensure their skills fit into a clear framework, are utilised and are evaluated. The training is based on skills identified as important by local workers in their own context, and focuses on developing change agent skills, such as working intersectorally, with communities and policymakers. The training program, through its focus on intersectoral collaboration and the participation of workers from a variety of institutions, is designed to create linkages and a critical mass of expertise. Working both bottom-up and top-down enhances the potential for sustained change in health promotion capacity in the Pacific Islands.

Another important consideration in building capacity in these small island countries is the role of external agencies.
It needs to be recognised that their contribution can be much greater than mere technical support, and that their potential political and strategic influence needs to be acknowledged and harnessed if best results are to ensue.

\section{REFERENCES}

1. Cox K. Persuading colleagues to change: Fifteen lessons learned from more than 20 years of trying. Education for Health 1999. 12(3), 347-353.

2. Paul S. Discussion Paper No.5-Capacity building for health sector development. New York: Division of Analysis, Research and Assessment, World Health Organization; 1995. Report No.WHO/SHS/NHP/95.8.

3. Crowder LV. Human resource and institutional capacity building through agricultural education. New York: Food and Agriculture Organization Research, Extension and Training Division, 1996. www.fao.org/sd/Exdirect/ EXan0015.htm

4. Sheng YK and Mohit RS. Understanding Capacity Building. Human Settlements Development Program, Asian Institute of Technology. www.hsd.ait.ac.th/capacity/UC2.HTM.

5. Secretariat of the Pacific Community (SPC), Pacific Island School for Health Promotion, Phase 1 Consultancy, unpublished report, 1998.

6. World Health Organization. The Ottawa Charter on Health Promotion, Ottawa: WHO, 1986.

7. World Health Organization. The Yanuca Island Declaration on Health in the Pacific in the 21st Century. Manila: World Health Organization Regional Office for the Western Pacific, 1995.

8. World Health Organization. The Rarotonga Agreement towards Healthy Islands. Manila: World Health Organization Regional Office for the Western Pacific, 1997.

9. World Health Organization. The Palau Action Statement on Healthy Islands. Manila: World Health Organization Regional Office for the Western Pacific, 1999.

10. Goodlee F. The World Health Organization: WHO Fellowships-what do they achieve? BMJ 1995:310(6972); 110-112.

11. La Fond A. The sustainability problem. Sustaining Primary Health Care. London: Earthsean, 1995: 23-38. w

\title{
CAPACITY BUILDING FOR PUBLIC HEALTH: A STATEWIDE PERSPECTIVE
}

\section{Doris Zonta}

Public Health Physician

NSW Department of Health

\author{
Andrew Wilson \\ Chief Health Officer \\ NSW Department of Health
}

\section{WHAT DOWE MEAN BY CAPACITY AND CAPACITY BUILDING AT A SYSTEM LEVEL?}

The word capacity is used in a number of different ways and is often related to ability (real or potential aptitude or skill), power or authority (duty, position or role), and capability (power to produce, perform or deploy). ${ }^{1}$ The word capacity when applied to the public health system can be taken to refer to the system's ability to perform or produce desired outcomes.

Human systems consist of organisations that, in turn, consist of individuals. The ability of the system to produce desired results depends on the performance of the constituent organisations, and the relationships between the organisations. The performance of an organisation depends on its leadership; on the effectiveness of the 
structures and processes through which the organisation functions; on the deployment of resources within the organisation; and on the knowledge, skills and commitment of the individuals that make up the organisation.

Capacity is a neutral word, conveying neither positive nor negative qualities. Capacity building, on the other hand, implies a deliberate effort to create, support or strengthen capacity. Hawe et al. (1999) identify three ways of thinking about capacity building: building infrastructure, building partnerships and building problemsolving capabilities. ${ }^{2}$

The infrastructure required for an effective public health system consists broadly of five elements: surveillance and information systems; a knowledgeable and skilled workforce; research and development capacity; legislation; and policy, planning and management systems. ${ }^{3}$ Partnerships require, firstly, effective leadership and relationship skills; and second, attention to structures, processes and resources in order to ensure sustainability. ${ }^{3}$ Generic problem-solving skills create the ability to respond flexibly and innovatively to new challenges. This requires an organisational culture that values learning and innovation.

\section{BUILDING PUBLIC HEALTH CAPACITY AT A STATEWIDE LEVEL}

In March 1999 the Chief Health Officer initiated a project, Future Directions for Public Health in New South Wales, aiming to set the medium-term priorities for public health in New South Wales. This project, which was conducted under the guidance of a broadly representative steering committee, represents the first significant review of public health in NSW for ten years or more. ${ }^{4}$

The priority areas that were considered focused not just on health issues and determinants of health, but on the partnerships and infrastructure required to improve the effectiveness of the public health system. Consultations and workshops across the Department and Areas during
1999 identified important strengths in the NSW public health system; and also identified a number of system issues.

The network of Public Health Units and the Area Health Services are regarded by many as significant strengths of the current system, although opportunities to further enhance both were also identified. The Public Health Unit network is seen as particularly successful in its capacity to develop local responses to issues, its response to infectious disease issues, and its capacity to provide specialist expertise to the Areas. The role of Health Promotion Units was also strongly supported. The particular strengths of the Area Health Services are seen as their broad public health role and the emphasis on health improvement.

Aspects of the current arrangements that were most often identified as requiring improvement included: funding and accountability arrangements, intersectoral communication and partnerships, clarity of roles and responsibilities, and workforce development.

A major output of the Future Directions project will be the development of a strategic directions statement for public health in NSW, to be released in 2000. This statement will support capacity building initiatives across the public health system.

\section{REFERENCES}

1. Websters On-Line Dictionary www.m-w.com/dictionary.htm.

2. Hawe P, King L, Noort M, Jordens C, Lloyd B. Indicators to help with capacity building in health promotion. NSW Department of Health and the Australian Centre for Health Promotion, Department of Public Health and Community Medicine, University of Sydney, 2000.

3. National Public Health Partnership. A planning framework for public health practice: a system perspective (draft). September, 1999.

4. Effective partnerships for public health. Working party paper prepared for the Steering Committee on Future Directions for Public Health in New South Wales. Sydney: NSW Department of Health, 1999. it: 